\title{
Effect of the various post and core systems in the fracture resistance of endodontically treated teeth: In-vitro study
}

\author{
${ }^{1}$ Tarek R. Abdelrehim, ${ }^{2}$ Essam A Khedr \\ ${ }^{1}$ Associate Professor, Department of Oral and Maxillofacial Prosthodontics, Faculty of Dentistry, King Abdulaziz University, KSA. \\ ${ }^{2}$ Lecturer, Fixed Prosthodontics Department, Faculty of Dentistry, Mansoura University, Egypt.
}

Correspondence Author: Tarek R. Abdelrehim, Department of Oral and Maxillofacial Prosthodontics, Faculty of Dentistry, King Abdulaziz University, KSA E-mail:- tabdalrahem@kau.edu.sa

Received date: 10 January 2019, Accepted date: 25 February 2018, Online date: 28 February 2019

Copyright: (C) 2019 Tarek R et al, This is an open-access article distributed under the terms of the Creative Commons Attribution License, which permits unrestricted use, distribution, and reproduction in any medium, provided the original author and source are credited.

\begin{abstract}
Background: The effect of different post and core systems on the fracture resistance of ceramic crowns placed on endodontically treated teeth has not been clearly recognized. Dentists usually select post and core system that supply best retention, support and decrease the possibility of root fracture. Objectives: The aim of this in-vitro study was to evaluate the fracture resistance of endodontically treated teeth restored with various post and core systems. The post and core systems used were fiber post,carbon fiber, zirconia and cast post and core. Compressive test was performed until fracture occurred. The fracture resistance of each specimen was recorded. Statistical analysis was completed using (SPSS/version 20) software. Numerical data were defined using mean and standard deviation for normally distributed data. Comparison between more than two populations was analyzed using F-test (ANOVA) followed by Post Hoc test "by Tukey method" to detect the level of significant between each two groups Results: The fracture resistance of fiber post and core, carbon fiber post was $566.3 \mathrm{~N}$ and $549.2 \mathrm{~N}$ respectively. For cast post and core it was $532.2 \mathrm{~N}$. Teeth restored with zirconia post showed fracture resistance of 426.3 N.Conclusion: it can be concluded that teeth restored with fiber post showed the highest resistance to fracture, while that restored with zirconia post showed lower fracture resistance. Teeth restored with fiber post, carbon fiber and cast posts showed no statistically significant difference in their fracture resistance.
\end{abstract}

Keywords: Fracture resistance, zirconia post, fiber post, cast post, and core.

\section{INTRODUCTION}

Restoration of endodontically treated teeth always creates challenging to the dentist. The extensive coronal hard tissue defects in endodontically treated teeth usually present a higher danger of biomechanical failure and fracture than the vital teeth, as result of the loss of structural integrity (Soares et al 2008). The removal of tooth structure during endodontic treatment and the presence of carious dentin, rather than little moisture content and increase brittleness decreases tooth resistance to fracture (Maroulakos et al 2015). Several kinds of post and core system have been introduced in dentistry. Metal post and cores such as gold and nickelchromium posts are commonly used. Prefabricated such as titanium and stainless-steel posts also used. Now the growing demand for aesthetic restorations provides reasoning for tooth-colored core (Schwart et al 2004 and Heydecke et al 2002). Newly, nonmetallic posts such as fiber-reinforced composite and zirconia posts have been introduced as theoretically suitable substitute materials (Ferrari et all 2000, Akkayanet al 2002, and Lanza et al 2005).

One of the roles of post and core is to increase the tooth durability by scattering the functional forces along the root length. The materials of post and core are one of the factors influencing the stress distribution in dentin. Many researchers have studied the distribution of stress in post and core systems. They used different theoretical or experimental methods (Germany et al 2008 and Ahangari et al 2008).

There are many conflicting views about the better choice of post material in the publication. Still, the best modulus of elasticity for a post has been debated, the matter stays discussed. Rigid post and core may support restorations better and dispense stress more consistently; though, if the tooth is over-loaded, a disastrous failure, like a deep or vertical root fracture may occur (Pilo et al 2002). Under high loads, a more elastic post may twist, leading to failure or floss of the restoration, but will leave the root sound for retreatment (Maccari et al 2003 and Cormier et al 2001). Though, a flexible post may allow moving of the restoration and compromise the luting agent. Next leakage can occur leading to secondary caries. 
Citation: Tarek R, et al., Effect of various post and core systems in the fracture resistance of endodontically treated teeth: In-vitro study. Australian Journal of Basic and Applied Sciences, 13(2): 60-63. DOI: 10.22587/ajbas.2019.13.8

The objective of the present in-vitro study was to evaluate the fracture resistance of teeth restored with various post and core systems.

\section{MATERIALS AND METHODS}

Thirty-two extracted human mandibular premolar teeth were chosen for this study. All the teeth were selected similarly in shape, size and root anatomy. Teeth were identical by measuring the mesiodistal and buccolingual measurement at the cementoenamel junction using vernier caliper (Chengdu Chengling Tools Group Co, China), allowing a deviation of 5\% from the mean. Teeth were cleaned and stored in artificial saliva from extraction until preparation for the study. The teeth were arbitrarily divided into four different groups $(n=8)$. For each group, one type of post system was used. Group I: teeth restored with fiber posts (Rely X, 3M ESPE, Germany) size 1, diameter 1.3mm. Group II: CF Carbon fiber posts (J Morita Corp, USA), size L2, diameter 1. 25mm.Group III: Zirconia post-Cercon (Degu Dent, Hanau, Germany). Group IV: Cast post and core, NickelChromium alloy (Wiron 99, Bego, Germany).

The coronal parts of all the teeth were removed parallel to cementoenamel junction using a diamond disc with water spray coolant keeping $2 \mathrm{~mm}$ of sound tooth structure above the cementoenamel junction to provide the ferrule. Standard endodontic procedures were carried out on all teeth. Standard files (K file, Mani, Japan), cleaning and shaping using 5.25\% sodium hypochlorite, step-back technique (master apical file 40). The canal was then obturated using lateral condensation technique using gutta-percha points (Dentsply, Maillefer, Switzerland) and eugenol-free sealer (AH26, Dentsply, De Trey, Germany). Post space of $10 \mathrm{~mm}$ length was prepared in all groups by removing gutta-percha using peso reamer (Dentsply, Maillefer, Switzerland). All posts were cemented with dual-cured resin luting agent (Bistite II DC, Tokuyama America, Inc.) following the manufacturer's recommendations.

In all groups, the core height is standardized to 5mm.In groups, I and II, composite resin cores (3M ESPE Filtek Supreme, USA) were build up. For group III and IV, acrylic resin patterns were fabricated by Duralay (Reliance Dental Manufacturing, IL, USA). For group III the duralay was scanned and the pre-sintered zirconia was milled by Cercon machine, and in group IV the duralay was cast by Nickel-Chromium alloy.

A minimum of 24 hours elapsed before any crown preparation. All teeth were prepared for all-ceramic crowns with a circumferential shoulder finish line located on sound tooth structure $1.0 \mathrm{~mm}$ from the cement-enamel junction. It was placed apical to the border of the core. Crown preparations were finished with six degrees taper, $5 \mathrm{~mm}$ axial wall height, and a flat occlusal surface. Impressions were taken with Polyvinyl siloxane impression material (President, Coltene, Whaldent, Switzerland) in a custom made a copper band. Conventional crowns were made from lithium disilicate (e-max, Ivoclar, Vivadent Schaan, Liechtenstein). The inner surfaces of the restorations were etched with hydrofluoric acid 5\%, pretreated by silane coupling agent and cemented with a dual-cure resin cement (Variolink II, Ivoclar, Vivadent). All samples were kept in $0.9 \%$ saline for 48 hours before measured. It was thermocycling for 500 cycles between $5^{\circ} \mathrm{C}$ and $55^{\circ} \mathrm{C}$ with 1 -minute dwell time. Samples were kept in distilled water for 24 hours before testing. Each specimen was mounted to the depth of $1 \mathrm{~mm}$ apically from cement-enamel junction in special made stainless steel tube using acrylic resin (Major Italy). It is used to hold the specimen during testing. Samples of each group were exposed to compressive test was by the Universal testing machine (Instron Corp, Canton, USA) at a crosshead speed of $0.5 \mathrm{~mm} /$ minute until fracture happened. The fracture resistance (maximum load to failure) was measured. Statistical analysis of the data: Data were fed to the computer using IBM SPSS software package version 20.0. Quantitative data were described using mean and standard deviation for normally distributed data. For normally distributed data, comparison more than two population were analyzed F-test (ANOVA) to be used, followed by Post Hoc test "by Tukey method" to detect the level of significance between every two groups.

\section{RESULTS}

The Fracture resistance values of all groups were recorded in Newton $(\mathrm{N})$, mean and standard deviation was calculated and a comparison between different groups are shown in (Table 1). A significant difference between the different groups was detected. The fiber posts with composite core displayed the highest fracture resistance $(566.3 \mathrm{~N})$, while the zirconia posts showed the lowest fracture resistance $(426.3 \mathrm{~N})$. For carbon fiber post, the fracture resistance was $(549.2 \mathrm{~N})$, while for cast post and core the fracture resistance was (532.2). Although higher values of fracture resistance were recorded with fiber post, the comparison with carbon fiber and cast post and core the difference was not statistically significant $(\mathrm{P} \geq 0.05)$. While for zirconia posts, the differences between the groups were statistically significant $(\mathrm{P} \leq 0.05)$.

Table (1): Comparison between different post systems.

\begin{tabular}{|l|l|l|l|l|}
\hline & $\begin{array}{l}\text { Group I } \\
\text { "Fiber Post" }\end{array}$ & $\begin{array}{l}\text { Group II } \\
\text { "Carbon fiber Post" }\end{array}$ & $\begin{array}{l}\text { Group III } \\
\text { "Zirconia post" }\end{array}$ & $\begin{array}{l}\text { Group IV } \\
\text { "Cast post and core" }\end{array}$ \\
\hline Range & $510.0-607.0$ & $508.0-615.0$ & $387.0-462.0$ & $498.0-572.0$ \\
Mean & 566.3 & 549.2 & 426.3 & 532.2 \\
S.D. & 40.61 & 31.3 & 27.6 & 36.13 \\
\hline ANOVA & 18.2 & \multicolumn{3}{|l}{} \\
P & $0.013^{*}$ & 0.245 & $0.012^{*}$ & 0.34 \\
\hline P1 & \multicolumn{3}{|l|}{$0.022^{*}$} & 0.271 \\
\hline P2 & & & $0.029^{*}$ \\
\hline P3 & & & \\
\hline
\end{tabular}


Citation: Tarek R, et al., Effect of various post and core systems in the fracture resistance of endodontically treated teeth: In-vitro study. Australian Journal of Basic and Applied Sciences, 13(2): 60-63. DOI: 10.22587/ajbas.2019.13.8

ANOVA test to compare between the four groups followed by post hoc test

P1 "comparison between group I and other groups II, III and IV"

P2 "comparison between group II and both groups III, IV"

P3 "comparison between group III and IV"

$\mathrm{P}$ “significant if $\leq 0.05$ ”

\section{DISCUSSION}

Perfect post and core system should have the following characteristics: Even distribution of functional force and stress along root surface to prevent root fracture, physical features like to dentin, highest retention with slight elimination of dentin, good retention to core, aesthetic compatibility with the final restorations, easily used (Butz et al 2001 and Martinez et al 1998). In this study to resemble the clinical situations, natural teeth were used instead of artificial teeth. This is because artificial teeth do not simulate natural dentin and not simulate clinical conditions. Natural teeth differ in size, length, and width, the presence of surface defects and cracks and location and shape of root canals (Ottl et al 2002). In this study measuring the buccolingual and mesiodistal dimension at the cementoenamel junction standardized teeth to make sure that each group includes teeth of identical dimensions. For core buildup material, the composite was the preferred material because of its good bond strength, appropriate compressive strength, good aesthetic and fast setting. It has a higher resistance to fracture than glass ionomer and amalgam. (Abou Rass et al 1992, and Kovarik et al 1992).

Although the fiber post showed higher resistance to fracture, no statistically significant difference was found between fracture resistance of teeth restored with fiber post, carbon fiber post, and cast post and core system. This was in agreement with the results obtained by Al-Wahadni et al 2008, and Sharma et al 2016. Also in another study done by Atash et al in 2017, they observed no significant difference in resistance to fracture between glass fiber post and metal post. In 2018 Nokar et al used three-dimensional finite element analysis to inspect the stress distribution of different post and core systems in radicular dentin. The results of this investigation showed that metallic cast post and cores displayed the least amount of stress concentration. It induces lower stresses in dentin. Abduljawad et al in 2017 concluded that the position of glass fiber posts enhanced the fracture resistance of endodontically treated anterior teeth with cervical cavities.

The fiber reinforced post and carbon fiber post has a very good modulus of elasticity near to dentin. This helps in improving the resistance to fracture of endodontically treated teeth. Great modulus of elasticity would let the post to tolerate a great amount of pressure before twisting and transferring the load to the root. This action makes the tooth more resistance to fracture.

In this study Zirconia post and core system showed lower fracture resistance than fiber, carbon fiber, and cast post and core. This was in agreement with what obtained with the finding of Hablibzadeh et al 2017 who concluded that fracture resistance of zirconia post and core was found to be significantly lower than those of fiberglass and cast nickel chromium post systems. Saritha et al in 2017 found that zirconia had good fracture resistance compared to glass fiber and carbon posts. Abduljabar et al 2012, found that zirconia post showed higher fracture resistance than fiber and cast post and core. This was in controversy with our findings. Forberger et al 2008, found no significant difference between fiber post and zirconia post. Cast post and the core of 1.4 $\mathrm{mm}$ diameter displayed high fracture resistance. Also, milled zirconia post presented acceptable result with lesser diameter post and core. (Soundar et al 2014).

In the present study, all samples were restored and tested with full coverage crown to simulate the clinical condition. Bultz et all; 2001_stated that the crown, when placed over the core buildup, creates a ferrule effect and variation in the load distribution, especially when the margin encircles a sound dentin collar. So testing post and core without placement of crown would not have reflected clinical condition. In some studies, teeth were restored by post and core only without crown restoration (Al-Wahdani et al 2006). This was not simulating the clinical condition. They said that the presence of crown might obscure the influence of different post and core systems (Regan et al 1999 and Patel et al 1996 ). Limitations of the study, that it was an in-vitro study, which may not reflect clinical conditions.

\section{CONCLUSIONS}

1. Teeth repaired with fiber-reinforced posts showed higher resistance to fracture.

2. Teeth restored with fiber, carbon fiber and cast posts showed no statistically significant difference in their fracture resistance.

3. Zirconia post and core system showed lower fracture resistance than fiber, carbon fiber, and cast post and core.

4. The long-term clinical study is required to assess clinical situations.

\section{REFERENCES}

Abduljawad M, Samran A, Kadour J,Al-Afandi M, and Ghazal M,2016. Effect of fiber posts on the fracture resistance of endodontically treated anterior teeth with cervical cavities: An in vitro study. J Prosthet Dent; 116; 80-84. DOI: 10.1016/j.prosdent.2015.12.011.

Abduljabbar T, Sherfudhin H, AlSaleh S Helal A, Al-Orini S, and Al-Aql N, 2012. Fracture resistance of three post and core systems in endodontically treated teeth restored with all-ceramic crowns. King Saud Uni J; 3:33-38. DOI: 10.1016/j.ksujds.2011.10.001.

Abou Rass M, 1992. Post and core restoration of endodontically treated teeth. Curr Opin Dent; 2:107-99. 
Citation: Tarek R, et al., Effect of various post and core systems in the fracture resistance of endodontically treated teeth: In-vitro study. Australian Journal of Basic and Applied Sciences, 13(2): 60-63. DOI: 10.22587/ajbas.2019.13.8

Ahangari A, Geramy A, and Valian A., 2008. Ferrule Designs and Stress Distribution in Endodontically Treated Upper Central Incisors: 3D Finite Element Analysis. J Dent (Tehran). 5(3): 105-110.

Akkayan B, and Gülmez T; 2002. Resistance to fracture of endodontically treated teeth restored with different post systems. J Prosthet Dent. 87(4): 431-437.

Al-Wahadni A,AlOmiri M, and Hatamleh M,2008. Fracture resistance of teeth restored with different post systems:In vitro study. Oral Surg Oral Med Oral Path Oral Radio Endod J; 106:77-83. DOI:10.1016/j.tripleo.2008.03.038.

Atash R, Arab M, Duteme H, and Cetik, 2017. Comparison of resistance to fracture between three types of permanent restorations subjected to shear force: An in vitro study. J Indian Prosthodont; 17(3): 239-249. DOI:10.4103/jips.jips_24_17.

Butz F, Lennon A M, Heydecke, G., and Strub, J, 2001. Survival rate and fracture strength of endodontically treated maxillary incisors with moderate defects restored with different post-and-core systems: an in vitro study. Int J Prosthodont; 14:58-64.

Cormier CT, Burns DR, and Moon P, 2001. In vitro comparison of the fracture resistance and failure mode of fiber, ceramic, and conventional post systems at various stages of restoration. J Prosthodont ; 10:26-36.

Ferrari M, Vichi A, and Garcia-Godoy F, 2000. Clinical evaluation of fiber-reinforced epoxy resin posts and cast post and cores. Am J Dent; 13:15-18.

Forberger N, and GöhringT, 2008. Influence of the type of post and core on in vitro marginal continuity, fracture resistance, and fracture mode of lithia disilicate-based all-ceramic crowns. J Prosthet Dent.100; 264-273. DOI: 10.1016/S00223913(08)60205-X.

Geramy A, Eghbal MJ, and Ehsani S, 2008. Stress distribution changes after root canal therapy in canine model: a finite element study. Iran Endod J.; 3(4): 113-118.

Habibzaden S, Rajati H,Haimiragha H,Esmailzadeh S, and Kharazifard M,2014. Fracture resistance of zirconia,cast Ni-Cr and fiber glass composite posts under all ceramic crowns in endodontically treated premolars. J Adv Prosthodont; 9: 170-175. DOI:10.4047/jap.2017.9,3.170.

Heydecke G, and Peters MC; 2002. The restoration of endodontically treated, single-rooted teeth with cast or direct posts and cores: a systematic review. J Prosthet Dent 87:380-386.

Kovarik RE, Breeding LC, and Caugham WF, 1992. Fatigue life of three resin core materials under simulated chewing condition. J Prosthet Dent; 68:584-590.

Lanza A, Aversa R, Rengo S, Apicella D, and Apicella A, 2005. 3D FEA of cemented steel, glass and carbon posts in a maxillary incisor. Dent Mater; 21(8): 709-715. DOI:10.1016/j.dental.2004.09.010.

Maccari PC, Conceicao EN, and Nunes MF, 2003. Fracture resistance of endodontically treated teeth restored with three different prefabricated esthetic posts. J Esthet Restor Dent; 15:25-30.

Maroulakos G, Nagy WW, and Kontogiorgos ED, 2015. Fracture resistance of compromised endodontically treated teeth restored with bonded post and cores: an in vitro study. J Prosthet Dent; 114:390-397. DOI:10.1016/j.prosdent.2015.03.017.

Martinez-Insuna A,Rilo B, and Santana U,1998. Comparison of the fracture resistances of pulpless teeth restored with a cat post and core or carbon fiber post with a composite core. J Prosthet Dent; 80:527-532.

Nokar S, Bahrami M, and Mostafay A, 2018. Comparative Evaluation of the Effect of Different Post and Core Materials on Stress Distribution in Radicular Dentin by Three-Dimensional Finite Element Analysis. J Dent (Tehran); 15(2): 60-78.

Ottl P,Hahn L,Lauer H, and Fay M,2002. Fracture characteristic of carbon fiber, ceramic and non-palladium endodontic post systems at monotonously increasing loads. J Oral Rehabil ; 29:175-183.

Patel A, and Gutteridge D, 1996.An in-vitro investigation of cast post and cores design. . J Dent; 24:155-161.

Pilo R, Cardash HS, Levin E, and Assif D, 2002. Effect of core stiffness on the in vitro fracture of crowned endodontically treated teeth. J Prosthet Dent; 88:302-306.

Regan SE,Fruits TJ,Van Brunt CL, and Ward CK,1999. Effects of cycling loading on selected post and core systems. Quintessence Int; 30:16-17.

Saritha M, Paul U, Keswani K Jhamb A, Mhatre S, and Sahoo P, 2017. Comparative Evaluation of Fracture Resistance of Different Post Systems. J Int Scc Prev Community Dent.7 (6): 356-359. DOI: 10.4103/JISPCD-413-17.

Schwart RS, and Robbin JW, 2004. Post placement and restoration of endodontically treated teeth: a literature review. J Endod ; 30(5): 289-301. DOI:10.1097/00004770-200405000-00001

Sharma S, Attokaran G,Singh K,Jerry J,Ahmed N, and Mitra N,2016 .Comparative evaluation of fracture resistance of glass fiber reinforced, carbon, and quartz post in endodontically treated teeth: An in-vitro study. Journal of International Society of Preventive and Community Dentistry; 6:373 -376.

Soares PV, Santos-Filho PC, Martins LR, and Soares CJ, 2008. Influence of restorative technique on the biomechanical behavior of endodontically treated maxillary premolars. Part I: fracture resistance and fracture mode. J Prosthet Dent. ; 99:30-37.DOI: 10.1016/S0022-3913(08)60006-2.

Soundar S ,Suneetha T,Angelo M, and Kovoor L,2014. Analysis of Fracture Resistance of Endodontically Treated Teeth Restored with Different Post and Core System of Variable Diameters: An In Vitro Study. J Indian Prosthodont; 14:144-150. DOI: $10.1007 / \mathrm{s} 13191-013-0346-7$. 